\title{
Radiological analysis of component positioning in total hip arthroplasty using the anterior approach
}

\author{
Dr M Deacon MBChB(UCT), DA(SA), HDip(Ortho), FC Ortho(SA) \\ Dept Orthopaedics, Prince Mysheni Memorial Hospital, Durban \\ Dr J de Beer MBChB(Pret), HDip(Ortho), FC Ortho(SA) \\ Specialist Orthopaedic Surgeon, Gateway Private Hospital and Alberlito Hospital, Durban \\ Dr P Ryan MBChB(UCT), HDip(Orth), MMed(Ortho), FC Orth(SA) \\ Dept Orthopaedics, Inkosi Albert Luthuli Central Hospital, Durban
}

\author{
Correspondence: \\ Dr Mark Deacon \\ Prince Mysheni Memorial Hospital \\ Griffiths Mxenge Highway \\ 4060 Umlazi \\ Email: mark@webspinners.co.za
}

\begin{abstract}
Background: The direct anterior approach for total hip replacement is gaining popularity among surgeons and patients alike, as it is a minimally invasive technique, and a true muscle-sparing operation. Reported advantages of this approach include decreased post-operative pain, faster post-operative mobilisation and a low incidence of hip dislocation.

Optimal component positioning is vital for the longevity of total hip replacements. Poor positioning leads to increased dislocation rates, accelerated bearing wear, limited range of motion and higher rates of revision surgery. Minimally invasive surgery strives for smaller incisions, and muscle-sparing dissection. This may result in poor acetabular exposure, and subsequent sub-optimal component positioning.

The direct anterior approach is generally done supine on a traction table with/without the use of intra-operative fluoroscopy. This study describes the surgical technique performed with the patient in the lateral decubitus position, without the use of traction, and without intra-operative imaging. We then report on the radiographic outcomes and complications using this approach.

Methods: We retrospectively reviewed 150 patients who had total hip replacements done via the direct anterior approach. Clinical notes were evaluated for patient demographics, body mass index, and post-operative complications. The post-operative radiographs were analysed for acetabular component position inclination and anteversion.

Results: The radiographic analysis showed a mean cup inclination of $41.1^{\circ}$ (range 27.9-61.1 ${ }^{\circ}$ ) and anteversion of $18.33^{\circ}$ (range 11.2-25.3 ${ }^{\circ}$. A total of $95.97 \%$ (95\% CI) of the components were within the safety zones, as described by Lewinnek, (inclination $40 \pm 10^{\circ}$, anteversion $15 \pm 10^{\circ}$ ). ${ }^{23}$ There were five outliers with regard to cup inclination. Three had excessively abducted cups, which were noted to be in patients with increased BMI $>35 \mathrm{~kg} / \mathrm{m}^{2}$. The remaining two were excessively adducted. There were no outliers with regard to cup anteversion.

There were no dislocations, deep infections or femoral nerve palsies. Two patients required re-operation: one for a periprosthetic fracture and another for a greater trochanter fracture with late displacement. There were six cases of thigh swelling which resolved on discontinuation of oral anti-coagulation, four episodes of soft tissue inflammation responding to physiotherapy, four clinically observed leg length discrepancies, two minor stitch abscesses, and two transient lateral cutaneous nerve palsies.

Conclusion: The direct anterior approach, done in the familiar lateral decubitus position, as described in this study, is safe and reliable, with an acceptable complication rate. The radiographic results for acetabular component placement are comparable to other surgical approaches, as well as to the direct anterior approach using a fracture table and intraoperative imaging.
\end{abstract}

Key words: anterior approach, total hip arthroplasty, component positioning 


\section{Introduction}

The direct anterior approach (DDA) for total hip arthroplasty was first described by Judet ${ }^{1}$ in 1947 and has more recently gained popularity for its attractive benefits of a faster recovery.,3

Reported advantages of the approach include less postoperative pain ${ }^{4}$ and less stringent post-operative hip precautions. ${ }^{5}$ There is a relatively low complication rate after the learning curve of the first $40-100$ cases $^{6.8}$ and the low dislocation rate makes it a particularly attractive approach. ${ }^{9,10}$

Any minimally invasive approach raises the concern whether the implant positioning can be accurately achieved. A smaller incision lends itself to poor visualisation and a higher risk of acetabular component malposition. ${ }^{11,12}$ This in turn is related to accelerated wear, ${ }^{13,14}$ component impingement, ${ }^{15,16}$ higher incidence of dislocation and an increased revision rate..$^{17,18}$

The majority of surgeons perform hip replacements with the patient in the lateral decubitus position through either an anterolateral, or posterior surgical approach. Currently the most common technique used for the DAA is positioning the patient supine on a traction table, and may also include intra-operative screening. If a surgeon wishes to begin using the DAA he has to contend with four changes to his/her routine arthroplasty practice: the approach, the patient position, the use of a traction table, and possibly an unfamiliar prosthesis (if the implant company provides the traction table).

We explore the accuracy of cup placement performed via the DAA in the lateral decubitus position without imaging and without the traction table of an experienced surgeon ( $>150$ cases) in this surgical approach which then negates the learning curve.

Using this method introduces only one variable, the approach. Therefore the lateral decubitus surgeon has a potentially less daunting learning curve.

\section{Material and methods}

We performed a retrospective chart and radiographic review of 150 primary direct anterior total hip replacements done between November 2013 and April 2015. Ethics approval was obtained for this study.

During this period, the majority of primary total hips were operated on using the DAA. Hips in which there was more than a $2.5 \mathrm{~cm}$ shortening, or which had a short varus femoral neck with restricted external rotation, were operated on through a standard posterior approach.

Patient parameters, demographic details, aetiology of hip pathology, body mass index and intra-operative or postoperative complications were recorded in the data sheet. The acetabular and femoral component sizes and bearing surfaces were noted.

The immediate post-operative X-rays of the pelvis were used for analysis of component positioning. These were true anterior-posterior views of the pelvis, centred over the pubis, including the most distal aspect of the femoral component, and were uploaded onto the Imatri software (www.imatri.net) for analysis by a surgeon not involved in the procedures (Figure 1). The acetabular cup inclinations and anteversion were measured using the predetermined morphing system. ${ }^{19}$

IBM SPSS version 22 was used for data analysis. Categorical variables were summarised descriptively using frequency tables and percentages. Continuous variables were summarised with mean, standard deviation and range. Scatterplots were constructed to visually assess points within the safety zones. After classifying radiographs as either inside, or outside the safety zones, factors associated with these outcomes were assessed using Pearson's chisquare tests or two-sided Fisher's exact tests as appropriate for categorical factors and t-tests for continuous predictors. A p-value $<0.05$ was considered as statistically significant.

\section{Surgical procedure used for hip replacements}

\section{Preparation and positioning}

Pre-operative templating is done for two important measurements. First if the opposite hip is normal, the native version is measured from this hip on the true $\mathrm{AP}$ pelvis so that this can be reproduced at the time of osteophyte debridement to improve accuracy of the local bony landmarks for cup orientation. Secondly the cup template is placed at 40 degrees inclination up against the medial wall and the relationship between cup and acetabular coverage at the 12 o'clock position noted. This is the most superior part of the acetabulum. ${ }^{20}$ This will act as an additional check for cup inclination during surgery.

The patient is positioned in the lateral decubitus position as for other approaches, but care is taken to place the anterior support over the symphysis pubis so as to ensure the anterior superior iliac spine (ASIS) is exposed and kept in the sterile surgical field. The surgeon stands in front of the patient as opposed to behind the patient for other approaches.

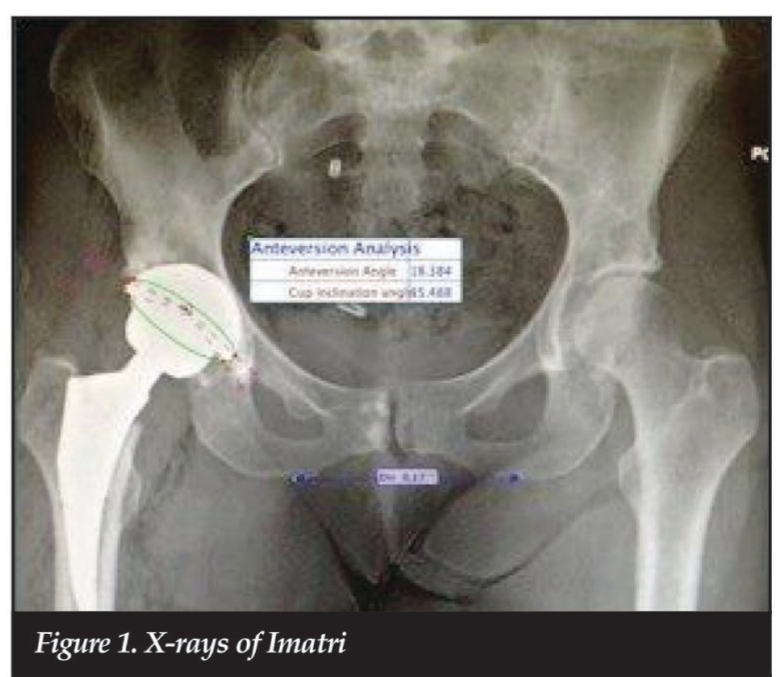




\begin{abstract}
Approach
The leg is prepped and freely draped. An 8 to $10 \mathrm{~cm}$ skin incision is made $2 \mathrm{~cm}$ lateral and inferior to the anterior superior iliac spine (ASIS) in the direction of the inferior border of the greater trochanteric tubercle (Figure 2). The tensor fascia lata (TFL) fascia is incised and the interval developed anterior to the TFL (Figure 3). A blunt Homan's retractor (24 Subtillis Switzerland) is used over the lateral femoral neck to retract the TFL laterally. This retractor has an additional curve at its waist matching the direction of the TFL fibres. This helps prevent cheese wiring of the muscle during retraction. The rectus femoris fascia is opened and the ascending branches of lateral femoral circumflex artery and veins coagulated (Figure 4). A second Homan's retractor is placed on the medial femoral neck. The rectus straight and reflected heads are identified and elevated before a partial anterior hip capsulectomy is performed (Figure 5). It is important to preserve the anterior and posterior aspects of the hip capsule. Anteriorly, the iliofemoral ligament helps reduce post-operative psoas tendinosis and helps as a checkrein to the femur, making it easier to deliver the greater trochanter over the rim of the acetabulum during femoral preparation.
\end{abstract}

A double-cut osteotomy of the femoral neck is performed in situ followed by removal of the napkin ring bony segment. This aids in the extraction of the femoral head (Figure 6). Acetabular exposure is achieved by the same Homan retractors now placed on the anterior and posterior walls of the acetabulum allowing visualisation for debridement of osteophytes and the labrum.

\section{Acetabular preparation and insertion}

Offset reamers and introducers are used, and the smallest reamer that produces a 360-degree fresh bony rim determines the chosen cup size (Figure 7).

At surgery four checks are performed to ensure adequate component placement:

1. The surgeon positions the patient himself. Once adequately positioned there should be a stable pelvis with leg length discrepancy the same in the lateral as in the supine position. There should be no pelvic adduction when viewed from posteriorly, and the pelvis and torso should be perpendicular to the floor and ceiling when viewed from the foot end of the bed.

2. The use of local bony landmarks and external alignment devices help determine anteversion.

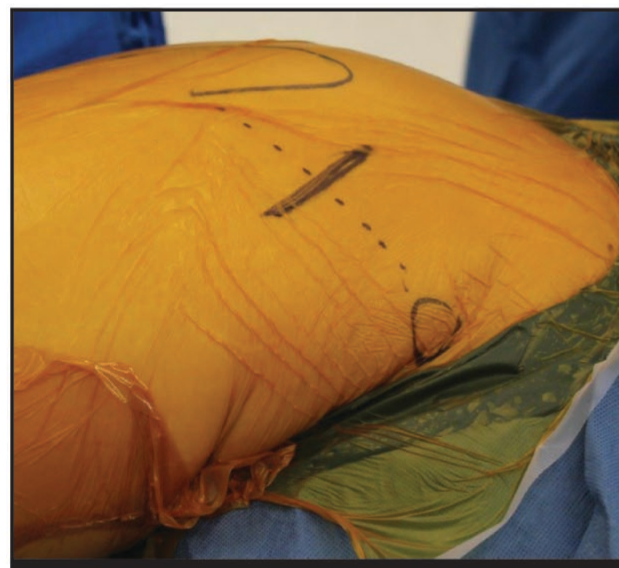

Figure 2. Patient positioning

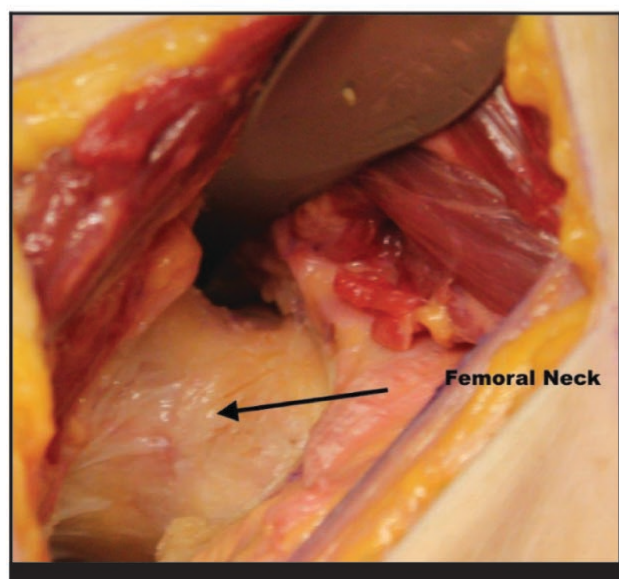

Figure 5. Femoral neck exposure

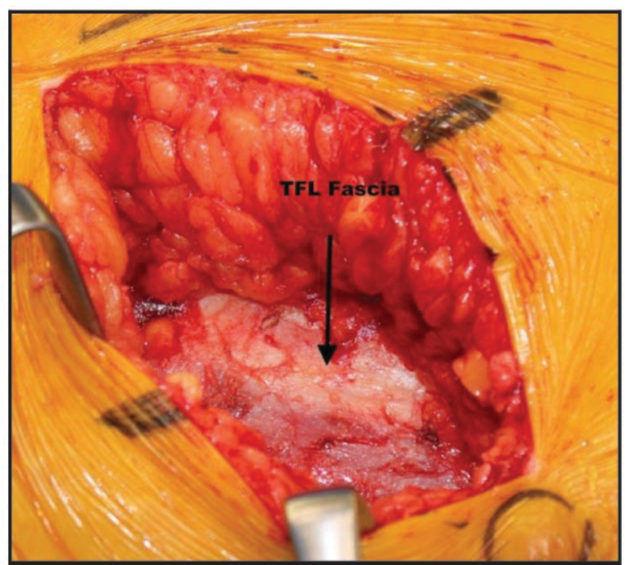

Figure 3. TFL fascia

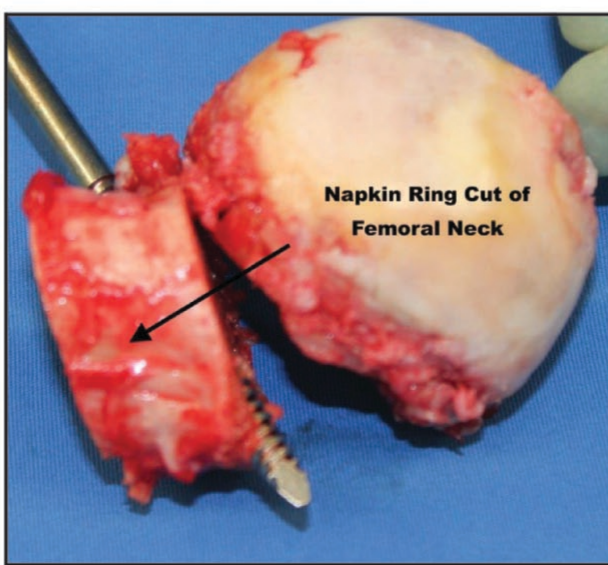

Figure 6. Napkin ring cut
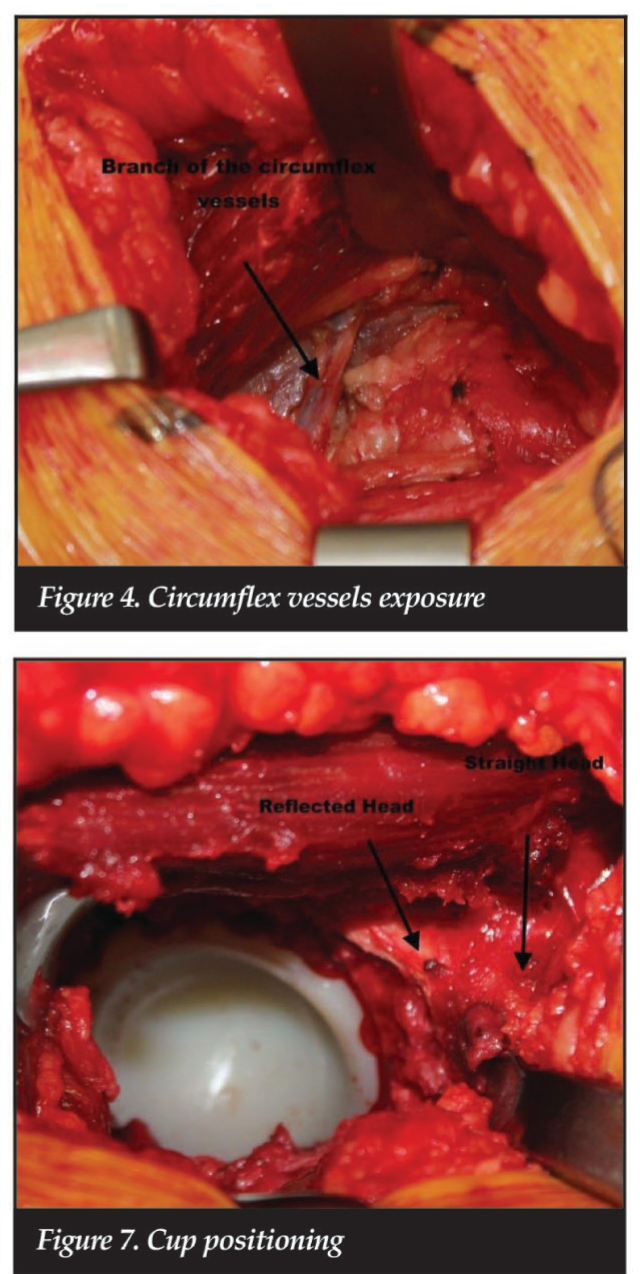

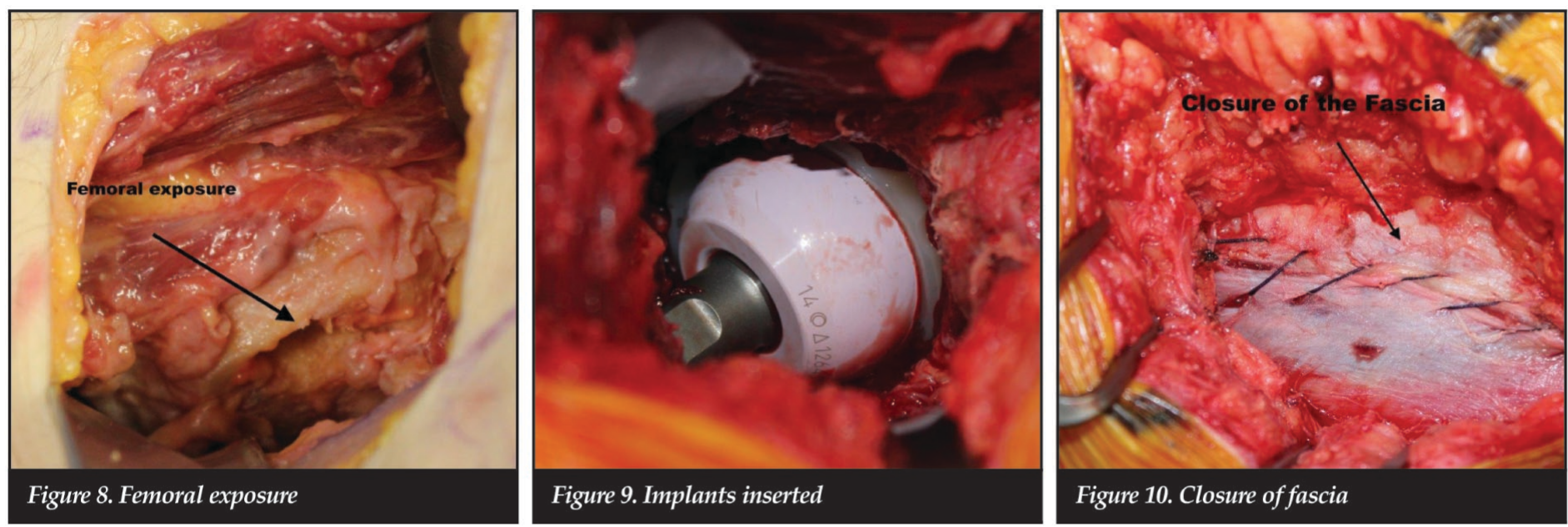

If the osteophytes have been removed the anterior and posterior walls will guide positioning of the cup. The reaming and cup introducer are referenced very well off the longitudinal axis of the thigh as the leg and the pelvis have not moved out of position as no joint dislocation was required prior to osteotomy.

3. Correct cup inclination is attained when the external alignment rod projects a line at 40 degrees between floor and ceiling. This is only accurate if the acetabulum is prepared prior to the femur, as the pelvis may move significantly with leg rotation. ${ }^{21,22}$ In the DAA, the hip is not dislocated prior to neck osteotomy and there is less pelvis movement from the time of patient positioning until the time of cup insertion.

The cup inclination can also checked by inspecting the lateral bony coverage, and comparing this to the pre-operative templating.

4. After femoral preparation and trialling, the hip is taken through a full range of motion to check for component-component, component-bone, or bonebone conflict. This assessment of combined anteversion is important in ensuring adequate hip stability without impingement and resultant dislocation.

\section{Femur preparation}

The femur is delivered with external rotation and extension, and a capsular release performed superiorly. The foot is placed in the sterile pouch that forms part of the hip drape. It is rare to release the posterior capsule or piriformis tendon in simple primary replacements. The anterior-inferior sling of the capsular attachment to the lesser trochanter (iliofemoral ligament) is kept intact, and this acts as a checkrein to prevent the femur from falling behind the acetabulum. The femur is then prepared and the implant trial inserted. Leg length and stability are assessed, and unimpeded full range of motion confirmed (Figure 8).
Once the implants are inserted, the following areas are infiltrated with local anaesthetic: the posterior aspect of the joint near the sciatic nerve, inferiorly at the obturator nerve, the anterior capsule near the femoral nerve, and the superficial area around the lateral femoral cutaneous nerve of the thigh. The fascia is closed over a $3 \mathrm{~mm}$ closed suction drain, and subcuticular sutures used for the skin (Figures 9 and 10).

\section{Results}

We reviewed the charts of 150 patients who had their total hip replacements performed through a DAA. The mean patient age at time of surgery was 62 years (range 32-87). There were $84(56.4 \%)$ female patients and $66(43.6 \%)$ male patients. Eighteen of the 150 had elevated BMIs $>35 \mathrm{~kg} / \mathrm{m}^{2}$. Sixty-one patients had left hip replacements while the remaining 89 were right-sided.

The vast majority (117 patients, $72.2 \%$ ) presented with primary osteoarthritis, $21(14.1 \%)$ had AVN, eight (5.3\%) with hip dysplasia and four $(2.66 \%)$ patients presented with neck of femur fractures (Table I).

The acetabular components used during these procedures were the Biomet Exceed ABT socket, with sizes ranging from 44 to 60 - the most common being either 48 or 52 . The acetabular liner was a polyethylene E1 liner in all, and the internal diameter either $32(68.75 \%)$ or $36(31.28 \%)$. A delta ceramic head was used in all.

The femoral components used were Biomet taperloc microplasty stems and the sizes ranged from 6 to 15 .

The radiographic analysis was performed using the online Imatri Morphology software, which calculates inclination, and anteversion in a predetermined morphology based on trigonometry of the eclipse generated. This showed a mean cup inclination of $41.07^{\circ}$ (range $27.9^{\circ}$ to $61.08^{\circ}$ ) and anteversion of $18.33^{\circ}$ (range $11.13^{\circ}$ to $25.3^{\circ}$ ) (Table II).

When plotted on a scatter graph the results showed that $95.97 \%(95 \% \mathrm{CI})$ of the acetabular cups were inserted in the safety zone as described by Lewinnek, ${ }^{23}$ (inclination $40 \pm 10^{\circ}$, anteversion $15 \pm 10^{\circ}$ ) (Graphs 1, 2 and 3). 


\begin{tabular}{|c|c|c|c|}
\hline \multicolumn{2}{|l|}{ Variables } & Values & $\begin{array}{c}\text { Percentage/ } \\
\text { range }\end{array}$ \\
\hline \multicolumn{2}{|c|}{ Age (mean/range) } & 62 & $(32-87)$ \\
\hline \multirow{2}{*}{$\begin{array}{l}\text { Gender } \\
(\%)(\mathrm{n})\end{array}$} & Male & 66 & $43.6 \%$ \\
\hline & Female & 84 & $56.4 \%$ \\
\hline \multirow{2}{*}{ BMI } & $<35$ & 132 & $88 \%$ \\
\hline & $>35$ & 18 & $12 \%$ \\
\hline \multirow{4}{*}{ Aetiology } & $\mathrm{OA}$ & 116 & $77.3 \%$ \\
\hline & Neck of femur fracture & 5 & $3.3 \%$ \\
\hline & Avascular necrosis & 21 & $14.1 \%$ \\
\hline & Hip dysplasia & 8 & $5.3 \%$ \\
\hline \multirow{2}{*}{$\begin{array}{l}\text { Side of } \\
\text { pathology }\end{array}$} & Left & 61 & $40.3 \%$ \\
\hline & Right & 89 & $59.7 \%$ \\
\hline
\end{tabular}

Table II: Component positioning in degrees

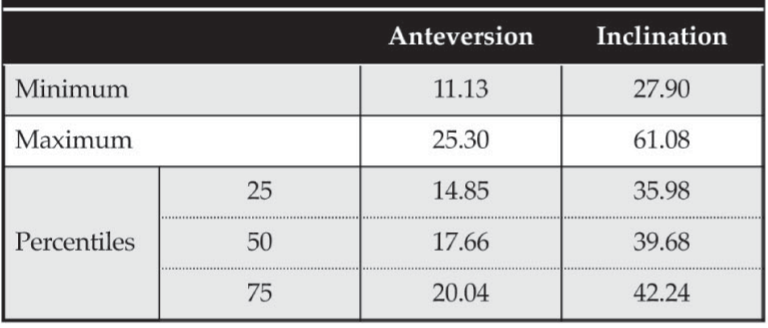

Seventy-two and a half per cent $(72.5 \%)(95 \% \mathrm{CI})$ of the component positioning for inclination was between $35^{\circ}$ and $45^{\circ}$, which was the surgeon's target range for optimal component positioning.

There was a significant association between elevated BMI over 35, and suboptimal component placement ( $\mathrm{p}=0.013$ ). Three out of the $18(17 \%)$ patients with elevated body mass indices had cup inclination angles over 50 degrees. The other outliers for cup malposition were closed cups and these patients were not obese.

There were no reported major complications such as dislocations, deep infections or femoral nerve palsies in this study.

There were four patients who presented with soft tissue complications. Two of these had rectus femoris pain, one had psoas tendinitis and the other patient reported iliotibial band pain - all resolved with physiotherapy and simple analgesics, and did not require further intervention.

There were two reported cases of transient lateral femoral cutaneous nerve numbness, and four cases of clinically relevant leg length discrepancy $(>1 \mathrm{~cm}$ difference compared to the opposite side). The leg length discrepancies were not validated on Imatri during the study.

Two patients required re-operation. One was for a greater trochanter fracture, which migrated and needed fixation. The other was for a periprosthetic fracture following a fall at six weeks. The fall resulted in femoral subsidence; however, the stem was deemed to be stable in the new position, and the hip required a longer head only.

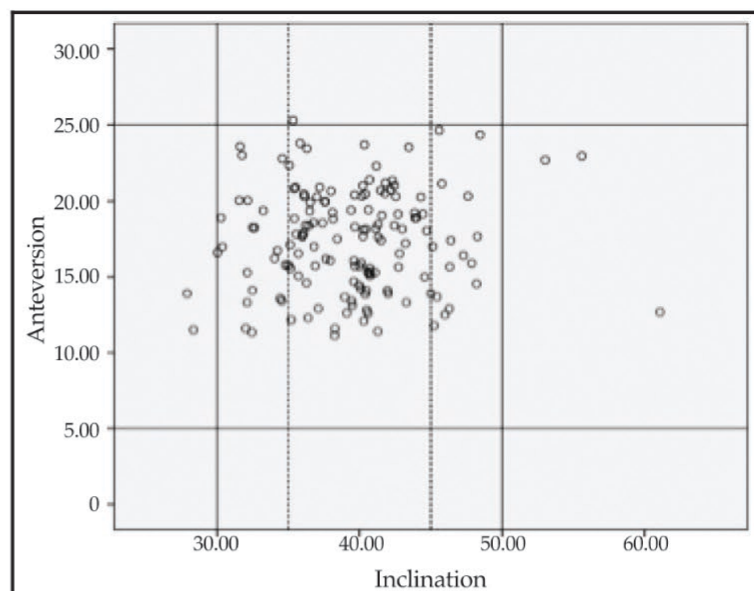

Graph 1. Scatter plot

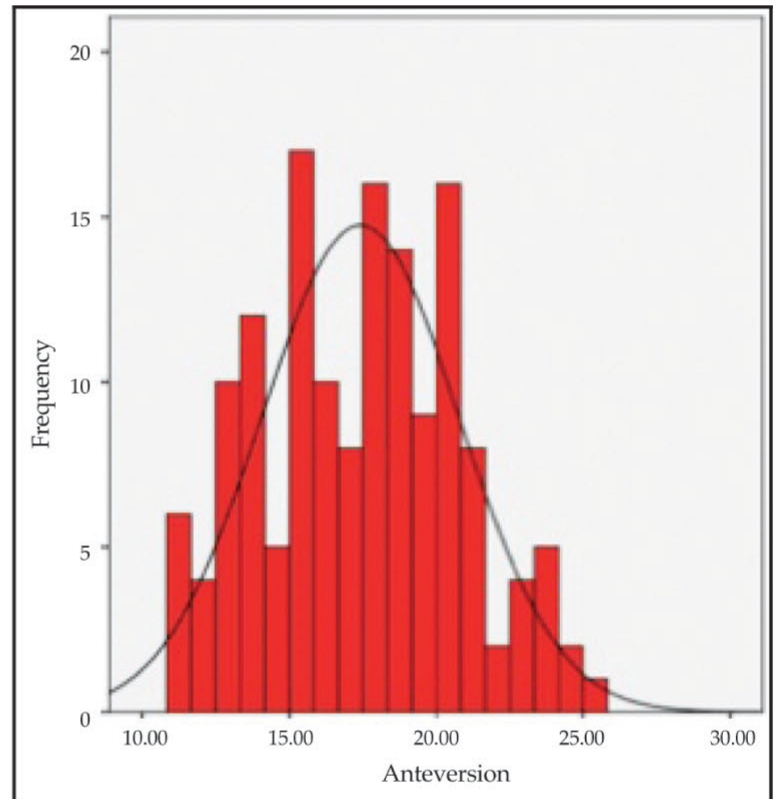

Graph 2. Bar graph: Anteversion

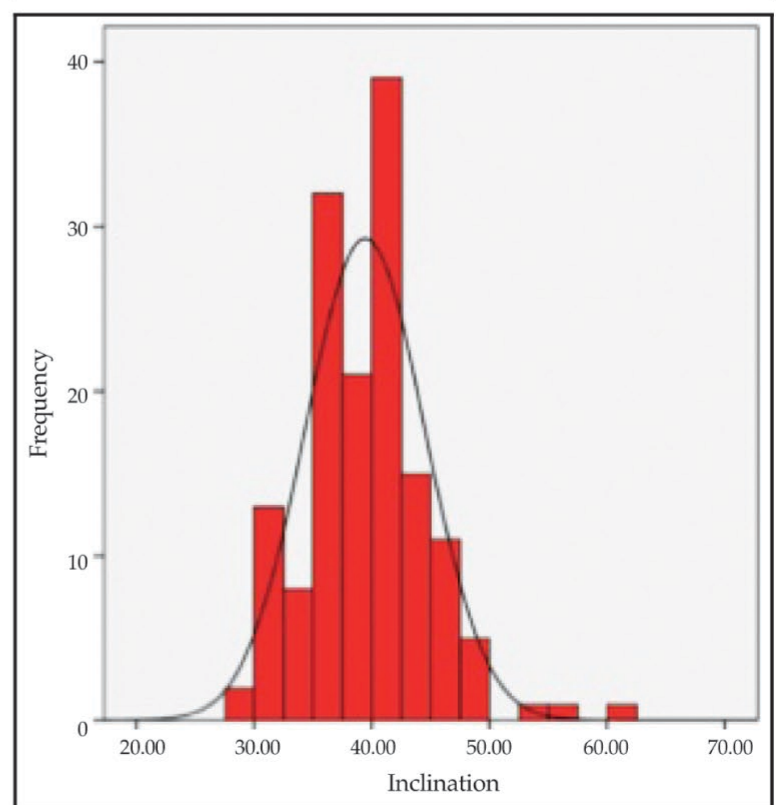

Graph 3. Bar graph: Inclination 
There were six cases of thigh swelling which resolved on discontinuation of oral anti-coagulation and three cases had minor wound breakdown, which necessitated regular dressings and resolved without surgery.

\section{Discussion}

A recent study published by Matta using the DAA with imaging and a fracture table showed comparable results. In his series of 437 consecutive patients they achieved an average inclination of $42^{\circ}$ with $96 \%$ of patients in Lewennik's safe $z^{2} e^{23}$ (range $35-55^{\circ}$ ) and average cup anteversion of $19^{\circ}$ with $93 \%$ in the safe zone (range $10-25^{\circ}$ ).

Nakata showed significantly more acetabular components were placed in 'safe zones' with the DAA (98 of 99 THA) compared to the posterior approach ( 87 of 96 THA). ${ }^{2}$

Other published results have also shown good results for cup positioning using the $\mathrm{DA}^{2426}$ with a large cohort study of 1152 patients having an average inclination of $42.1^{\circ}$ (SD 6.6) and anteversion of 19.2 (SD7.7). ${ }^{10}$

We had similar results with $95.5 \%$ of the cups inserted in the safe zone for inclination and only one outlier for anteversion according to Lewennik's prescribed zones.

In the early part of the study, three outliers were identified with excessively abducted cups, with all having raised BMI values above $35 \mathrm{~kg} / \mathrm{m}^{2}$. It is well documented that obesity renders accurate cup placement a challenge. ${ }^{27,28}$ When the shorter distal skin incision is used in these overweight patients, there is a tendency for the standard cup introducer to be pushed into a more vertical position, and therefore the cups are abducted in high BMI patients. Subsequently a higher offset acetabular introducer was used (Figure 11) which improved the inclination angles in these larger patients.

In the literature there are two commonly used references for safe zones for cup replacement; Lewinnek ${ }^{23}$ and McCollum and Gray. ${ }^{29}$ Both of these give a wide range of inclination for safe cup placement that does not take into account that inclination more than 45 degrees increases wear

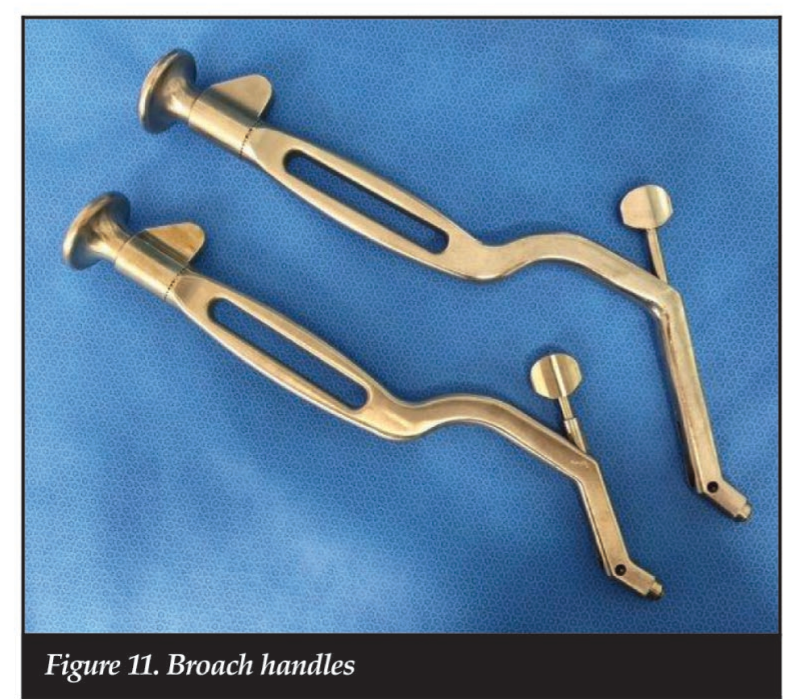

rates. ${ }^{13,14,30}$ While less than 35 degrees abduction reduces range of motion,,$^{15}$ this may increase impingement of the femoral neck on the cup which may result in wear, and/or dislocation. This in turn may result in higher revision rates. ${ }^{17}$ In this study the percentage of cases within the traditional safe zone was comparable with other studies but we feel, based on the more recent literature, that the traditional safe zones are too liberal.

These safe zones should be reconsidered if we expect to achieve longevity for our patients, especially with the advent of hard-on-hard bearings, which are even more unforgiving. ${ }^{17,31,32}$

When we analysed our results based on the aforementioned studies we found that only $72.5 \%$ of our patients were within the 35-45 degree safe zone for abduction.

We believe there are certain limitations to the DAA for hip replacements. This would be a limitation to our study in that approximately $10 \%$ of primary hip replacements did not fit our selection criteria for using the DAA. This 'cherry picking' may also improve the results for our cup positioning in this study as the very complex cases were treated through a posterior approach. These patients would have required either a rectus femoris reflected head release for acetabular exposure or a piriformis and posterior capsule release for femoral access. Clinically we observed our patients to have more groin pain at 6 weeks with leg elevation in a seated position or a straight leg raise in the supine position than the posterior approach patients if the reflected head was not preserved. Some DAA users routinely incise through reflected head ${ }^{5}$ but we found good visualisation even when preserving it. The piriformis and the posterior capsule are important dynamic and static stabilisers respectively. ${ }^{33}$ With a posterior approach the capsule and piriformis tendon get repaired and are at least more anatomical than no repair if the posterior capsule and piriformis are released through the DAA in a difficult primary procedure. Furthermore in complex cases with significant shortening the TFL has a higher risk of injury resulting in pain and swelling. If lacerated, it can cause a deformity of the upper lateral thigh, especially noticeable in thin patients.

Further studies are needed to determine whether the DAA still holds value with regard to improved early outcomes in complex primary and revision settings when compared to other approaches.

One of the reasons we believe our results are comparable to other studies despite not using imaging in theatre is that multiple references points are used for cup positioning rather than utilising only one parameter such as local bony landmarks, the transverse acetabular ligament, or external references. Pre-operative templating, the surgeon positioning the patient himself, corrected local bony landmarks with the transverse ligament and external alignment devices followed by immediate post-operative radiological feedback help to refine the cup placement. We also believe in the value of assessing a full range of motion with trial implants, not just looking for frank instability 
but also for subtle impingement. This is not easily done on a traction table unless the boot is detached from the traction device. Measuring the cup position immediately post-operatively improves the surgeon's accuracy of implantation.

When the hip is stable with no impingement through a full range of motion, the version is correct. If there is impingement however, the cup is changed to improve the longevity of the implant. ${ }^{34,35}$ If there is any posterior instability once leg length and offset have been optimised, there must be retroversion of the cup since the posterior stabilisers, namely the posterior capsule and piriformis, are left intact through this approach. Similarly, if there is over coverage of the cup at the anterior wall with anterior subluxation in leg extension, adduction and external rotation, the cup is excessively anteverted and must be corrected, provided there are no posterior osteophytes causing component-bone conflict. Supplemental screw fixation was required in only $3 \%$ of our acetabular implantations, so cup repositioning for subtle impingement or instability was simple. Repositioning was performed in $5 \%$ of our patients.

The literature reports a low dislocation rate for the DAA when compared to other approaches. Siguier's dislocation rate was $0.96 \%$ (10 out of 1037 ). ${ }^{36}$ Keggi and colleagues ${ }^{37}$ had a dislocation rate of $1.3 \%$ in their series of 2132 primary hips. Matta reported a rate of $0.6 \%$ and a large multi-centre observational study ${ }^{10}$ had the same low dislocation rate of $0.6 \%$ in 1152 total hip replacements done via the anterior approach.

We had no dislocations in this small series and we attribute this not only to the approach where the posterior stabilisers remain intact, but also to the good visualisation of the cup and its version through surgery. Being willing to change the position of the cup in the presence of subtle impingement further reduces the risk for dislocation and should improve implant longevity. Saving the piriformis attachment preserves the most important dynamic posterior stabiliser of the hip.

\section{Conclusion}

Our study showed similar results to other studies with improved accuracy of acetabular component positioning using the direct anterior approach. It differs from other literature in that the patient positioning remains unchanged from the lateral decubitus positioning that many high volume surgeons are familiar with rather than the patient positioned supine on a traction table. There is also no imaging in theatre during implantation. Further clinical studies are needed to see if this approach can reduce implant impingement and dislocation rates, which would make it an attractive approach for improving implant longevity and reducing re-operation rates.

\section{Compliance with Ethics Guidelines}

Dr De Beer is a consultant for Smith and Nephew and Zimmer Biomet.
Drs Deacon and Ryan declare no conflict of interests.

All procedures followed were in accordance with the ethical standards approved by the UKZN biomedical research ethics committee. Informed consent was obtained from all patients being included in this study.

\section{References}

1. Judet J. The use of an artificial femoral head for arthroplasty of the hip joint. J Bone Joint Surg Br. 1950;32-B: 166-73. Pubmed Central PMCID: 15422013.

2. Nakata $K$, Nishikawa $M$, Yamamoto $K$, Hirota $S$, Yoshikawa H. A clinical comparative study of the direct anterior with mini-posterior approach: two consecutive series. The Journal of arthroplasty. 2009 Aug;24(5):698-704. PubMed PMID: 18555653.

3. Restrepo C, Parvizi J, Pour AE, Hozack WJ. Prospective randomized study of two surgical approaches for total hip arthroplasty. The Journal of Arthroplasty. 2010 Aug;25(5):671-79 e1. PubMed PMID: 20378307.

4. Goebel S, Steinert AF, Schillinger J, Eulert J, Broscheit J, Rudert M, et al. Reduced postoperative pain in total hip arthroplasty after minimal-invasive anterior approach. International orthopaedics. 2012 Mar;36(3):491-98. PubMed PMID: 21611823. Pubmed Central PMCID: 3291765.

5. Restrepo C, Mortazavi SM, Brothers J, Parvizi J, Rothman RH. Hip dislocation: are hip precautions necessary in anterior approaches? Clinical Orthopaedics and Related Research. 2011 Feb;469(2):417-22. PubMed PMID: 21076896. Pubmed Central PMCID: 3018228.

6. Berend KR, Lombardi AV, Jr., Seng BE, Adams JB. Enhanced early outcomes with the anterior supine intermuscular approach in primary total hip arthroplasty. The Journal of Bone and Joint Surgery American volume. 2009 Nov;91 Suppl 6:107-20. PubMed PMID: 19884418.

7. Spaans AJ, van den Hout JA, Bolder SB. High complication rate in the early experience of minimally invasive total hip arthroplasty by the direct anterior approach. Acta orthopaedica. 2012 Aug;83(4):342-46. PubMed PMID: 22880711. Pubmed Central PMCID: 3427623.

8. Masonis J TC, Odum s. Safe and accurate: Learning the direct anterior total hip arthroplasty. Orthopedics. 2008;31. Pubmed Central PMCID: 1929801

9. Matta JM SC, Ferguson T. Single Incision anterior approach for total hip arthroplasty on an orthopaedic table. Clinical Orthopaedics and Related Research. 2005;441:115-24. Pubmed Central PMCID: 16330993.

10. Anterior Total Hip Arthroplasty Collaborative I, Bhandari M, Matta JM, Dodgin D, Clark C, Kregor P, et al. Outcomes following the single-incision anterior approach to total hip arthroplasty: a multicenter observational study. The Orthopedic Clinics of North America. 2009 Jul;40(3):329-42. PubMed PMID: 19576400.

11. Woolson ST MC, Syquia JF, Lannin JV, Schurman DJ,. Comparison of primary total hip replacements performed with a standard incision or a mini incision. The Journal of Bone and Joint Surgery American volume. 2004;86(7):1353-58.

12. Teet JS, Skinner HB, Khoury L. The effect of the 'mini' incision in total hip arthroplasty on component position. The Journal of Arthroplasty. 2006 Jun;21(4):503-507. PubMed PMID: 16781401. 
13. Wan Z, Boutary M, Dorr LD. The influence of acetabular component position on wear in total hip arthroplasty. The Journal of Arthroplasty. 2008 Jan;23(1):51-56. PubMed PMID: 18165028.

14. Little NJ, Busch CA, Gallagher JA, Rorabeck $\mathrm{CH}$, Bourne RB. Acetabular polyethylene wear and acetabular inclination and femoral offset. Clinical Orthopaedics and Related Research. 2009 Nov;467(11):2895-900. PubMed PMID: 19412648. Pubmed Central PMCID: 2758973.

15. Kummer FJ SS, Lyer S, et al. The effect of acetabular cup orientations on limiting hip rotation. The Journal of Arthroplasty. 1999;14(4):509-13.

16. D'Lima DD UA, Buehler KO, et al. The effect of the orientation of the acetabular and femoral components on the range of motion of the hip at different head neck ratios. The Journal of Bone and Joint Surgery American volume. 2000;82(3):315-21.

17. Sugano N NT, Miki H et al. Mid-term results of cementless total hip replacement using a ceramic on ceramic bearing with and without computer navigation. J Bone Joint Surg Br. 2007;89(4):455-60.

18. Hassan DM JG, Dust WN. et al. Accuracy of intraoperative assesment of acetabular prosthesis placement. The Journal of Arthroplasty. 1998;13(1):80-84.

19. Dymond IW, Ashforth JA, Dymond GF, Spirakis T, Learmonth ID. The usage of image trigonometry in bone measurements. Hip international: the Journal of Clinical and Experimental Research on Hip Pathology and Therapy. 2013 Nov-Dec;23(6):590-95. PubMed PMID: 24062220.

20. Nishikubo Y, Fujioka M, Ueshima K, Saito M, Kubo T. Preoperative fluoroscopic imaging reduces variability of acetabular component positioning. The Journal of Arthroplasty. 2011 Oct;26(7):1088-94. PubMed PMID: 21676577.

21. DiGioa AM JB, Blackwell M et al. Image guided navigation system to measure intraoperatively acetabular implant alignment. Clinical Orthopaedics and Related Research. 1998;355:8-22.

22. Asayama I, Akiyoshi Y, Naito M, Ezoe M. Intraoperative pelvic motion in total hip arthroplasty. The Journal of Arthroplasty. 2004;19(8):992-97.

23. Lewinnek G, Lewis J, Tarr R. Dislocations after total hipreplacement arthroplasties. The Journal of Bone and Joint Surgery American volume. 1978;60((2)):217-20.

24. Barrett WP, Turner SE, Leopold JP. Prospective randomized study of direct anterior vs postero-lateral approach for total hip arthroplasty. The Journal of arthroplasty. 2013 Oct;28(9):1634-38. PubMed PMID: 23523485.

25. Alexandrov $\mathrm{T}$ AE, Menendez LR. Early clinical and radiographic results of minimally invasive anterior approach hip arthroplasty. Advances in Orthopedics. 2014.

26. Hallert O, Li Y, Brismar H, Lindgren U. The direct anterior approach: initial experience of a minimally invasive technique for total hip arthroplasty. Journal of Orthopaedics and Related Research. 2012;7:17. PubMed PMID: 22533964. Pubmed Central PMCID: 3419665.
27. Todkar M. Obesity does not necessarily affect the accuracy of acetabular cup implantation in total hip replacment. Acta Orthop Belg. 2008;74(2):206-209.

28. Callanan MC, Jarrett B, Bragdon CR, Zurakowski D, Rubash HE, Freiberg AA, et al. The John Charnley Award: risk factors for cup malpositioning: quality improvement through a joint registry at a tertiary hospital. Clinical Orthopaedics and Related Research. 2011 Feb;469(2):319-29. PubMed PMID: 20717858. Pubmed Central PMCID: 3018230.

29. McCollum DE Gray WJ. Dislocation after total hip arthroplasty. Causes and prevention. Clinical Orthopaedics and Related Research. 1990;261:159-70.

30. Tower SS CJ, Currier BH, et al. Rim cracking of the cross linked longevity polyethylene acetabular liner after total hip arthroplasty. The Journal of Bone and Joint Surgery American volume. 2007;89(10):2212-17.

31. Hart AJ, Ilo K, Underwood R, Cann P, Henckel J, Lewis A, et al. The relationship between the angle of version and rate of wear of retrieved metal-on-metal resurfacings: a prospective, CT-based study. J Bone Joint Surg Br. 2011 Mar;93(3):315-20. PubMed PMID: 21357951.

32. De Haan R, Pattyn C, Gill HS, Murray DW, Campbell PA, De Smet K. Correlation between inclination of the acetabular component and metal ion levels in metal-onmetal hip resurfacing replacement. J Bone Joint Surg Br. 2008 Oct;90(10):1291-97. PubMed PMID: 18827237.

33. Moussallem CD HF, Lahoud JC. Incidence of piriformis tendon preservation on the dislocation rate of total hip replacement following the posterior approach: a series of 226 cases. J Med Liban. 2012 Jan-Mar;60(1):19-23. Pubmed Central PMCID: 22645897.

34. Shon WY, Baldini T, Peterson MG, Wright TM, Salvati EA. Impingement in total hip arthroplasty a study of retrieved acetabular components. The Journal of Arthroplasty. 2005 Jun;20(4):427-35. PubMed PMID: 16124957.

35. Yamaguchi M AT, Bauer TW, et al. The spatial location of impingement in total hip arthroplasty. The Journal of Arthroplasty. 2000;15(305).

36. Siguier T SM, Brumpt B. Mini-incision anterior approach does not increase dislocation rate: a study of 1037 total hip replacement. Clinical Orthopaedics and Related Research. 2004;426:164-73.

37. Keggi Jk, Hou. HM, Zatorski. LE. Anterior approach to total hip replacement: surgical technique and clinical results of our first one thousand cases using noncemented prostheses. Yale Journal of Biology and Medicine. 1993;66:243-56.

This article is also available online on the SAOA website (www.saoa.org.za) and the SciELO website (www.scielo.org.za). Follow the directions on the Contents page of this journal to access it. 